\title{
The Sorting of Female Careers after First Birth A Competing Risks Analysis of Maternity Leave Duration
}

Arntz, Melanie; Dlugosz, Stephan; Wilke, Ralf

Document Version

Accepted author manuscript

Published in:

Oxford Bulletin of Economics and Statistics

DOI:

10.1111/obes.12158

Publication date:

2017

License

Unspecified

Citation for published version (APA):

Arntz, M., Dlugosz, S., \& Wilke, R. (2017). The Sorting of Female Careers after First Birth: A Competing Risks Analysis of Maternity Leave Duration. Oxford Bulletin of Economics and Statistics, 79(5), 689-716.

https://doi.org/10.1111/obes.12158

Link to publication in CBS Research Portal

\section{General rights}

Copyright and moral rights for the publications made accessible in the public portal are retained by the authors and/or other copyright owners and it is a condition of accessing publications that users recognise and abide by the legal requirements associated with these rights.

Take down policy

If you believe that this document breaches copyright please contact us (research.lib@cbs.dk) providing details, and we will remove access to the work immediately and investigate your claim. 


\title{
The Sorting of Female Careers after First Birth: A Competing Risks Analysis of Maternity Leave Duration Melanie Arntz, Stephan Dlugosz, and Ralk A. Wilke
}

\author{
Journal article (Accepted manuscript)
}

This is the peer reviewed version of the following article: Arntz, M., Dlugosz, S., \& Wilke, R. (2017). The Sorting of Female Careers after First Birth: A Competing Risks Analysis of Maternity Leave Duration. Oxford Bulletin of Economics and Statistics, 795), 689-716. 001: 10.1111/obes.12158, which has been published in final form at https://doi.org/10.1111/obes.12158.

This article may be used for non-commercial purposes in accordance with Wiley Terms and Conditions for Self-Archiving.

Uploaded to CBS Research Portal: January 2019 


\title{
The Sorting of Female Careers after First Birth: A Competing Risks Analysis of Maternity Leave Duration *
}

\author{
Melanie Arntz ${ }^{\dagger}$ \\ Stephan Dlugosz ${ }^{\ddagger}$ \\ Ralf A. Wilke ${ }^{\S}$
}

July 2016

\begin{abstract}
A number of contributions have found evidence that motherhood is a critical life event for women's employment careers. This study presents a detailed analysis for the duration of maternity leave in which young mothers can make a transition into different types of employment, unemployment as well as the next birth. We provide a comprehensive picture of the sorting mechanisms that lead to the differentiation of women's employment careers after birth. Our empirical evidence is derived from large linked administrative individual labour market data from Germany for a period of three decades. We obtain unprecedented insights how women's skills, the quality of the previous job match, firm level characteristics, labour market conditions and leave legislation are related to the length of maternity duration. Expansionary leave policies, e.g., are found to be a key factor for the rising share of women who have their second child out of inactivity.
\end{abstract}

Keywords: work interruptions, cumulative incidence, leave legislation

JEL: C41, J13, J18

*We thank Conny Wunsch and the participants at various seminars and conferences for their feedback on this work. We also thank the research data centre at the Institute for Employment Research for the support with the data. Financial support from the German Research Foundation (DFG) through the grant FI692/9-2 is gratefully acknowledged.

†ZEW Mannheim, L7.1, D-68161 Mannheim, and University of Heidelberg, E-mail: arntz@zew.de

†EW Mannheim, L7.1, D-68161 Mannheim, E-mail: stephan.dlugosz@googlemail.com

${ }^{\S}$ Copenhagen Business School, Department of Economics, Porcelænshaven 16A, DK-2000 Frederiksberg, E-mail: rw.eco@cbs.dk 


\section{Introduction}

The transition to motherhood can be considered a critical life event for women's subsequent employment careers. Whereas prior to the first birth a high and increasing share of women are working full-time, there appears to be a strong differentiation of career paths afterwards with many women returning only part-time or not returning at all (Angrist and Evans 1998, Lundberg and Rose 2000, Gjerdingen and Center 2005, Baxter et al. 2008, Schober 2013, Fitzenberger et al. 2013). In fact, Gustafsson et al. (1996) find that differences in female labour force participation across Sweden, Germany and Great Britain are solely due to postbirth differences. In Germany, the impact of first birth on women's subsequent careers appears to be stronger than in other European countries as shown by Gutierrez-Domenech (2005). Among those employed one year before birth, only around 50 percent are working five years after birth compared to two thirds in most other countries. Moreover, this share of working mothers is only few percentage points higher than two years after birth.

In addition, there are numerous studies suggesting persistent wage losses from motherhood that seem to be largely driven by birth-related work interruptions and the subsequent return to reduced working hours (Waldfogel 1997; Budig and England 2001; Phipps et al. 2001; Baum 2002; Gangl and Ziefle 2009; Viitanen 2012). Moreover, these wage penalties appear to be quite pronounced for Germany (Schönberg and Ludsteck 2007; Beblo et al. 2009). Hence, birth-related careers interruptions appear to be an important determinant of the family and gender wage gap as has already been suggested by Mincer and Polacheck (1974). However, some studies suggest that at least parts of the wage penalty do not seem to have a causal nature, but are driven by the selection processes surrounding birth. While controlling for unobservable 
differences between women with and without children does not substantially reduce the wage penalty for most studies ${ }^{1}$, Winder (2008) suggests that the wage penalty for the US disappears when taking acount of the negative selection of women into birth with respect to their prebirth wage growth. Apparently, women with a poor labour market performance have higher subsequent fertility rates, hence biasing the wage penalty upward. Ejrnæs and Kunze (2013), on the other hand, demonstrate that the wage penalty in Germany is upward biased due to a selection of less productive women into post-birth employment. They hence argue that the rather high wage penalties for women with small children that have been found in Germany are biased by conditioning on a sample of women that returned to work. They hence propose to have a closer look at the selection processes that are taking place after birth.

In fact, even among women who give birth to their first child and have all been working fulltime prior to birth, the related work interruption leads to a strong differentiation of subsequent labour market paths as suggested by Figure $1^{2}$. The figure shows the proportion of German women who end their birth-related work interruption by either returning to their previous job in full-time or part-time, by taking up a job with another employer, delivering another child or starting a period of unemployment, education or training. In addition to suggesting a strong differentiation of women's labour market paths after birth, the figure also indicates that there have been notable changes across the observation period between 1980 and 2000 such as an strong increase in the incidence of giving birth to the second child out of leave-related inactivity. This rasies the question as to what drives this differentiation process. The answer to this question is of high concern for mothers, employers and the economy as a whole. For employers,

\footnotetext{
${ }^{1}$ As an exception, Andersson et al. (2003) find strongly reduced and Korenman and Neumark (1992) even insignificant wage penalties from motherhood once controlling for unobserved heterogeneity within a fixed effects framework.

${ }^{2}$ For details on the data source and definition see section 3.
} 
Figure 1: Share of observed transitions after inactivity by year of birth, 1985-2005.

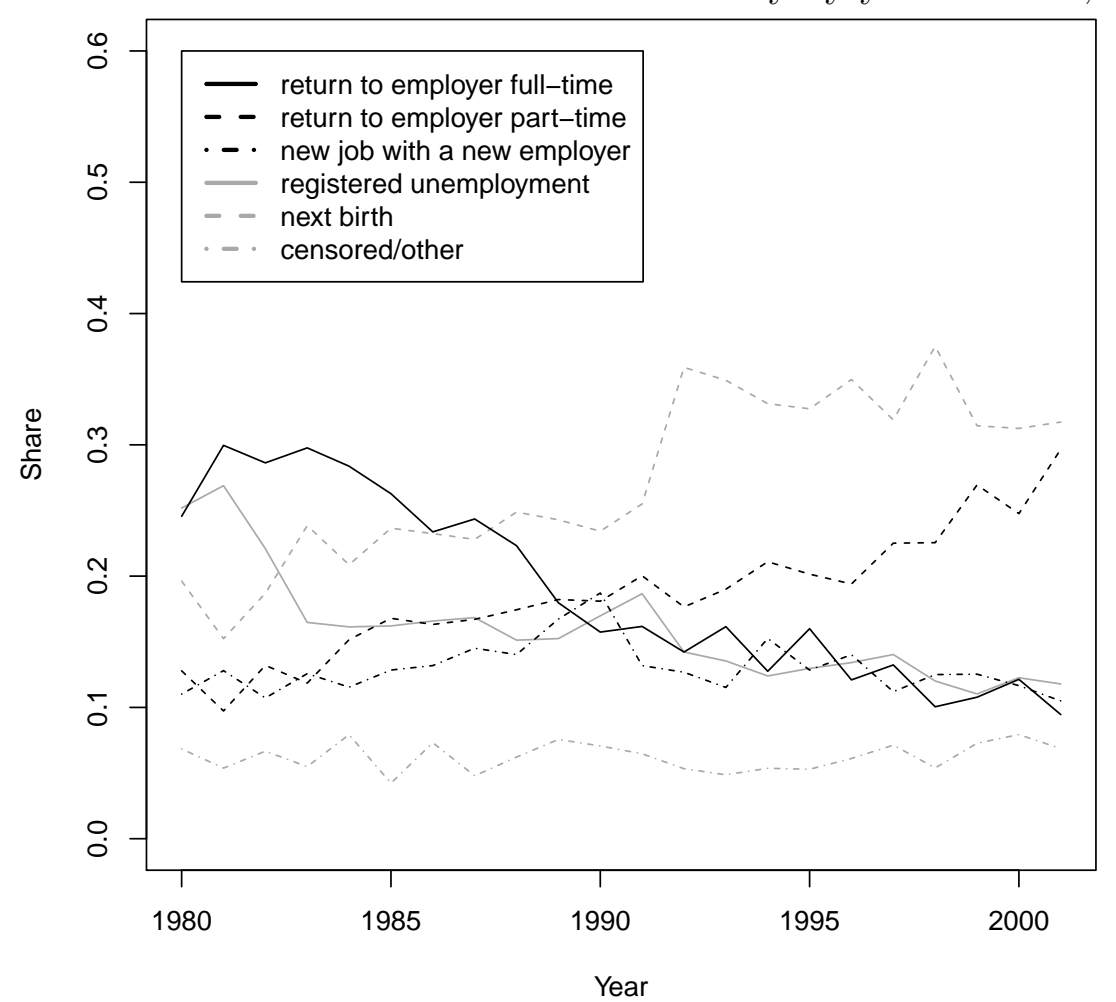

work interruptions, especially by women with long tenure and good job performances, are costly because firm-specific human capital may get lost and can be substituted for only by a costly hiring and training process of new employees (Alewell and Pull 2001). Moreover, a fast return to the pre-delivery employer has been found to reduce the wage loss from motherhood (Baum 2002; Waldfogel 1997; Phipps et al. 2001; Ziefle 2004) which is desirable both from the perspective of mothers as well as the economy as a whole. Furthermore, staying attached to the labour market should be preferable from the individual as well as societal perspective if future career options are to be preserved. Hence, whether, when and how a mother returns to the labour market after a child-related work interruption becomes a crucial research question.

Therefore, the goal of this paper is to gain deeper insights into a woman's decision process after first birth. We do so by estimating a competing risk model for the out of work duration of previously full-time employed mothers who can return to either of the states shown in Figure 1. 
We examine how the return decision is related to various factors such as women's productivity, the pre-delivery job match quality, the characteristics of the previous employer, leave policies, labour market conditions, and child care availability. We can perform such a detailed analysis because we use German administrative individual data for a period of more than two decades that records the exact date of births and the employment history including information on employers. Moreover, we can exploit changes in leave regulations, childcare availability and aggregate labour market conditions across a long period. This comprehensive approach closes several research gaps in the existing literature.

First of all, most of the literature focusses on the decision of women to return to either employment in general or the previous job. There are only few exceptions that also consider "next birth" (Lalive and Zweimüller, 2009), full- vs. part-time employment (Ondrich et al., 2000, Frodermann et al., 2013) or the probability to return to the previous employer (Schönberg and Ludsteck 2014). However, women can typically choose between a much broader range of options that may subsequently affect their employment careers. By allowing for a much broader range of career options within a competing risks model, our analysis improves our understanding of the decision when and how to return to the labour market since a negative relationship for one risk could otherwise be leveled out by a positive relationship for another risk.

Secondly, much of the literature focusses on the impact of leave policies only. By exploiting policy reforms for identification, most studies find that a longer maximum leave duration induces mothers to delay the job return, see Baum (2003) for the US, Hanratty and Trzcinski (2009) for Canada and Ondrich et al. (2003), Lalive and Zweimüller (2009), Schönberg and Ludsteck (2014) for Austria and Germany. Moreover, more generous leave policies also appear to be associated with reduced post-birth labour supply and wages, even though the evidence is not 
fully conclusive, see Gangl and Ziefle (2009) for a review. Compared to the numerous studies on the impact of leave policies, however, only few studies aim at a broader analysis of the determinants of women's return decision. For the US, Leibowitz et al. (1992) and Klerman and Leibowitz (1994), for example, focus on the impact of women's skills, family income and child care options. Fitzenberger et al. (2016) derive first detailed insights into the relationship of firm and individual characteristics and the distribution of maternity leave duration, but their analysis is restricted to employees from one large German firm. Our study contributes to this literature by examining the relevance of a broad set of factors in determining the post-birth differentiation in labour market states using a large random sample of individual administrative records covering a period of more than two decades. Hence, our results may help politics to design leave policies and employers to develop a human resource management that decrease the likelihood for long, potentially career-damaging out of work periods.

Thirdly, with the exception of Fitzenberger et al. (2013), Frodermann et al. (2013) and Fitzenberger et al. (2016), the literature estimates the probability of having returned to the labour market at one or a small number of time points using discrete choice models. Hence, the results do not provide a full picture of mothers' out of work duration and transition probabilities. We employ a competing risks duration model and construct conditional transition probabilities for any point of the out of work duration. In particular, we employ the semiparametric dependent competing risks model for cumulative incidences (Fine and Gray, 1999). This model does not impose parametric restrictions on the subdistribution baseline hazard functions and on the dependence structure between competing risks.

Finally, the German case is of particular interest for an international readership. Apart from the fact that motherhood seems to have a particularly pronounced effect on subsequent careers, 
there has been a period of expansionary parental leave policies since the 1980s. We are thus able to shed light on the relevance of the legislative framework in shaping labour market outcomes of mothers. Hence, our analysis should be of interest beyond Germany as many countries have adopted or consider similar maternity leave policies.

We find transition times to employment and unemployment clearly related to the design of leave legislation with mass transitions taking place at the time the mother looses some form of entitlement. We also find that extensive job protection periods of up to 3 years do not simply lead to a later return to the previous employer but are related with higher probabilities of making an employer change or giving birth to the second child towards the end of the job protection period. Thus our results cast some question marks on the economic sense of key elements of family policy in various European countries. At the same time we find evidence for provision of child care to be suited to reduce maternity related out of work duration.

The paper is structured as follows. Section 2 develops some hypotheses regarding the determinants of the decision when and how to return to the labour market. Section 3 describes the data and section 4 presents the duration model. Section 5 presents the main empirical results.

\section{A Framework for the Return Decision of Mothers}

In order to develop some plausible hypotheses regarding the processes that take place after giving birth, one needs to discuss the incentives for continuing the out of work period compared to alternative states that a mother might choose. This choice set and the related incentives are closely linked to the institutional setting. In Germany, there is a mother protection period (MPP) of two months after birth during which the mother may not return to work, but receives 
full salary in the meantime. Afterwards, a mother is entitled to a parental leave during which she may not be laid off by her pre-birth employer. This legally guaranteed job protection period (JPP) has been extended stepwise from 8 months in 1979 to 36 months since 1993, see Figure 4 (Appendix). In addition to this JPP, women may receive a means-tested benefit after the MPP. The entitlement period for this maternity benefit (MB) has been prolonged stepwise from 4 to 22 months between 1979 and 1993, see Figure 4 (Appendix). The corresponding maximum MB that a mother may receive thus also increased from a total of 1500 euros to almost 7000 euros during the entitlement period, see Figure 5 (Appendix). Still, these benefits are rather low compared to a full-time salary.

Hence, due to the institutional setup, mothers can decide to return to their previous employer at any time after the MPP as long as the maximum JPP has not been exhausted. Moreover, women can usually choose between returning full- or part-time. ${ }^{3}$ After the JPP, the employer need not re-employ the mother. However, having the next child within the JPP immediately renews both the entitlements to job protection as well as maternity benefits. Hence, having another child within the JPP is another option that a women may seek, at least if the JPP is long enough for actually having a next child within this period. If, for some reason, returning to the previous employer is not an attractive option, a woman may also seek entering a new job rather than returning to the old employer. If she has not found a job yet, she may also quit her previous job and register unemployed to possibly receive unemployment compensation. Finally, she may also decide to enter education or training, become self-employed or start a minor employment with only few working hours. Since of all these latter states tend to be rare,

\footnotetext{
${ }^{3}$ Since 2001, women are legally entitled to return part-time rather than full-time unless an employer proves that the job is not compatible with part-time work. Before 2001, there already had been a widespread and increasing acceptance of part-time work which was reflected in an increasing number of part-time-friendly collective labour agreements during the 1980s and 1990s.
} 
we pool them to a residual category. As a result, we distinguish between

1. returning to the same employer full-time,

2. returning to the same employer part-time,

3. entering a new job with a new employer,

4. registering unemployed and searching for a new job,

5. having the next child,

6. entering other state (education, training, self-employment, minor employment).

We assume that a woman stays at home as long as this option yields the highest discounted expected utility. She then switches to the state whose expected utility is the first to exceed the utility from staying home. ${ }^{4}$ Note that this is a simplification as two of these choices, namely having a next child and finding a new job, have a random element such that the time of transition to these states cannot be fully chosen. Still, the incentive to seek one or the other option should be driven by the corresponding expected utility. Hence, both the out of work duration as well as the transition state depend on the time-varying utility differential between staying home and all other states.

\footnotetext{
${ }^{4} \mathrm{~A}$ similar model for the return decision of the mother has already been dicscussed by Ondrich et al. (2000). More generally, the decision of mothers about the duration and exit state after maternity leave could be interpreted as a dynamic discrete choice model (compare Aguirregabiria and Mira, 2010). Although these models are a powerful tool for applied economic analysis, they are only identified under a number of identifying restrictions (compare Section 4). Given the large number of competing risks in our model and that some of these states can be entered upon the choice of the mother while others require search (such as finding a new employer), we apply a simple comparison of expected utilities of staying at home or changing to another state. We hence avoid restrictive assumptions on the dependence structure between competing risks, the distribution of covariates and parametric assumptions for the distributions of failure times.
} 
While the utility from staying home is given by the utility of caring for your child full-time plus the utility derived from receiving maternity benefits and having the option to return to the pre-birth employer within the job protection period, the utility derived from returning to work either in full-time, part-time or with a different employer clearly hinges on the expected future wage income and job satisfaction minus childcare costs. We thus assume that women are more likely to return to (full-time) employment early after birth, the higher a woman's productivity and the better the availability of childcare. Moreover, we hypothesise that mass transitions to employment occur when the utility of staying home drops markedly such as at the end of the MPP with full salary compensation, the end of the MB receipt and, especially, at the end of the JPP. With the expansion of these periods, we expect women to stay home longer. For transition intensities to states which do not require search, such as return to the previous employer, we expect sharp pronounced mass points at the kinks of the expected utility function. As pointed out by a reviewer we should expect search related transition intensities to increase already in advance of the kinks due to anticipating behaviour (Hausman and Woutersen, 2014). We expect that the probability of returning to the previous employer decreases with time and is lower for women with poorer pre-birth job matches. The underlying notion is that jobs with a high match quality as reflected in higher wages and longer tenures, increase the attachment to the previous employer. The longer a woman stays away from her old job, however, the weaker this attachment gets as firm-specific human capital depreciates on top of general human capital. In cases where a pre-birth job may prove to be incompatible with family responsibilities due to, for example, shift work or the lack of part-time schemes, a woman may, however, immediately seek alternative job offers. Hence, the availability of family-friendly job schemes at the previous workplace may be decisive for the return decision. 
Contrary to most other countries, officially registering unemployed prior to the end of the JPP may be a reasonable alternative for mothers in Germany if they don't want to return to their pre-birth job. Since the requirements for receiving unemployment transfers in terms of job search activities were not particularly high during the 1980s and 1990s, unemployment benefits may have provided a means to prolonging the period of receiving some benefits while staying at home. Hence, if women opt for registering unemployed for this reason, doing so when MB are exhausted, is a reasonable choice as they receive $67 \%$ of their pre-birth income if they claim unemployment benefits within the first year, but only $67 \%$ of a usually lower fictive wage income depending on their formal education afterwards. If they claim benefits after the JPP, the transfer receipt drops further as women may only apply for the lower and means-tested unemployment assistance. Note that within the JPP, registering unemployed would typically involve a voluntary quit ${ }^{5}$ that should (but may not always) result in a short suspension period for unemployment benefits before claimants are fully eligible afterwards. After the JPP, mothers and employers may seek a mutual agreement for the termination of the working contract, hence avoiding a suspension of transfer receipt.

We have thus identified a number of factors that likely affect a women's decision whether, when and how to return to the labour market after birth. In the next two sections, we will discuss how we aim to test these hypotheses empirically.

\footnotetext{
${ }^{5}$ An exception would be if women prior to birth had a fixed-term contract that ends within the JPP.
} 


\section{Data}

Our analysis uses biographical data in Germany (BASiD) that links administrative records from the German statutory pension insurance scheme (Rentenversicherung) and the Federal Employment Agency (Bundesagentur für Arbeit). The data comprise of individuals holding an active pension account at the end of 2009, i.e. who have at least one pension-relevant observation until 2009 and have not retired yet. Since most individuals collect pension-relevant spells during their education and work history, the 579,000 individuals that are included in the data constitute a $1 \%$ random sample of around $96 \%$ of the German population.

The data contain daily spell information about employment periods, periods of training and education and periods of registered unemployment. The data also contain information about salaries, basic demographic variables such as age and gender, firm characteristics and regional identifiers among others. The distinctive feature of these data compared to similar German administrative labour market data such as Integrated Employment Biographies (IEB) is that, in addition, they contain verified information about birth dates of own children. Thus, these data allow us to determine the time of delivery and therefore the begin of a maternity period. For more details about BASiD see Hochfellner et al. (2012). We restrict our sample to females aged 18-45 who give birth to their first child in the period 1985-2005 and who were full-time employed at the time of conception. This latter restriction ensures that we have a relatively homogeneous sample of women in terms of labour force attachment. As a matter of fact, the majority of $90.2 \%$ of all women who give birth for the first time work full-time prior to birth. This leaves us with 19,535 women whose first births took place between 1985-2005.

From these data we construct maternity leave periods. Maternity leave is not directly available 
in the data but is constructed from other information. By knowing the birth date of children and having information about various other labour market states, we define maternity leave as any unobserved period after delivery until the female is entering one of the six observable post-maternity states listed in the previous section. In our model, these risks are not assumed to be independent but there is independent censoring at end of data in 2009. Table 1 reports the number of observed transitions and the share of observed destination states in our sample. Around $38 \%$ of young mothers return to their former employer (around 20\% as part-timer) and around $13 \%$ change the employer. Over a quarter of women deliver their second child and add a subsequent maternity duration. Note that these women could return to their previous employer later on. In fact, the total share of women returning to the previous employer at some point amounts to $52 \%$. This is compatible with numbers from the German NEPS data ${ }^{6}$ that suggests that around $45 \%$ of all women return to their previous employer at some point after the first birth. While we could have modelled the next birth as simply prolonging the out of work duration rather than as a separate type of exit, we decided to explicitly look at these transitions as the institutional regulations likely affect the incidence of this state and likely prolong the out-of-work duration. Finally, a non-negligible share of $15 \%$ register unemployed, while only $2 \%$ exit to some other state. Fitzenberger et al. (2016) observe somewhat larger shares of return to the same employer and lower job separation shares but this might be attributed to the fact that their data is from one large firm only.

In order to get a first insight regarding the timing of these transitions while taking account of censored observations, Figure 2 presents nonparametric estimates of unconditional cumulative incidences for the risks of interest. The cumulative incidence refers to the probability of having

\footnotetext{
${ }^{6}$ NEPS refers to the adult survey of the National Educational Panel Study in Germany that contains extensive biographies of almost 12,000 adults in Germany born between 1956 and 1986.
} 
Table 1: Sample size and share of transitions into risks

\begin{tabular}{lrr}
\hline \hline Risk & Freq. & Percent \\
\hline Return to job full-time & 3,488 & 17.86 \\
Return to job part-time & 3,947 & 20.20 \\
Job with new employer & 2,490 & 12.75 \\
Unemployment & 2,969 & 15.20 \\
Next birth & 5,299 & 27.13 \\
Other employment/education & 447 & 2.29 \\
Right-censored & 895 & 4.58 \\
\hline Total & 19,535 & 100.00 \\
\hline \hline
\end{tabular}

experienced a transition to state $j$ at some time period $t$ in the presence of other competing risks. $^{7}$ Note that these cumulative incidences are on the grounds of pooled data from the period 1985-2005, hence spanning different institutional regimes as discussed in the previous section. Still, the cumulative incidences for returning to the previous employer in part-time jump visibly at 36 months which is the maximum length of job protection for young mothers after 1992, but we also see minor jumps when job protection ended under previous regimes. Return to the previous employer in full-time appears to be less concentrated around these expiry points compared to the return as a part-timer. Moreover, it is not surprising that there are hardly any transitions to the former employer after this period has elapsed. Using similar data, Schönberg and Ludsteck (2014) also find evidence for the returns taking place more likely around these points but only few in between or after 36 months. In contrast to Fitzenberger et al.'s (2016) results we do not observe considerable increases in cumulative incidences for the return after more than 3 years. Furthermore, as hypothesized previously, employer changes somewhat gain in importance relative to returning to the pre-birth employer after two years and

\footnotetext{
${ }^{7}$ The estimated cumulative incidences are obtained without assuming a specific dependence structure between competing risks. Conventional methods such as the Kaplan-Meier estimator normally require independent competing risks. Compare Kalbfleisch and Prentice (1980).
} 
Figure 2: Nonparametric estimates of unconditional cumulative incidences.
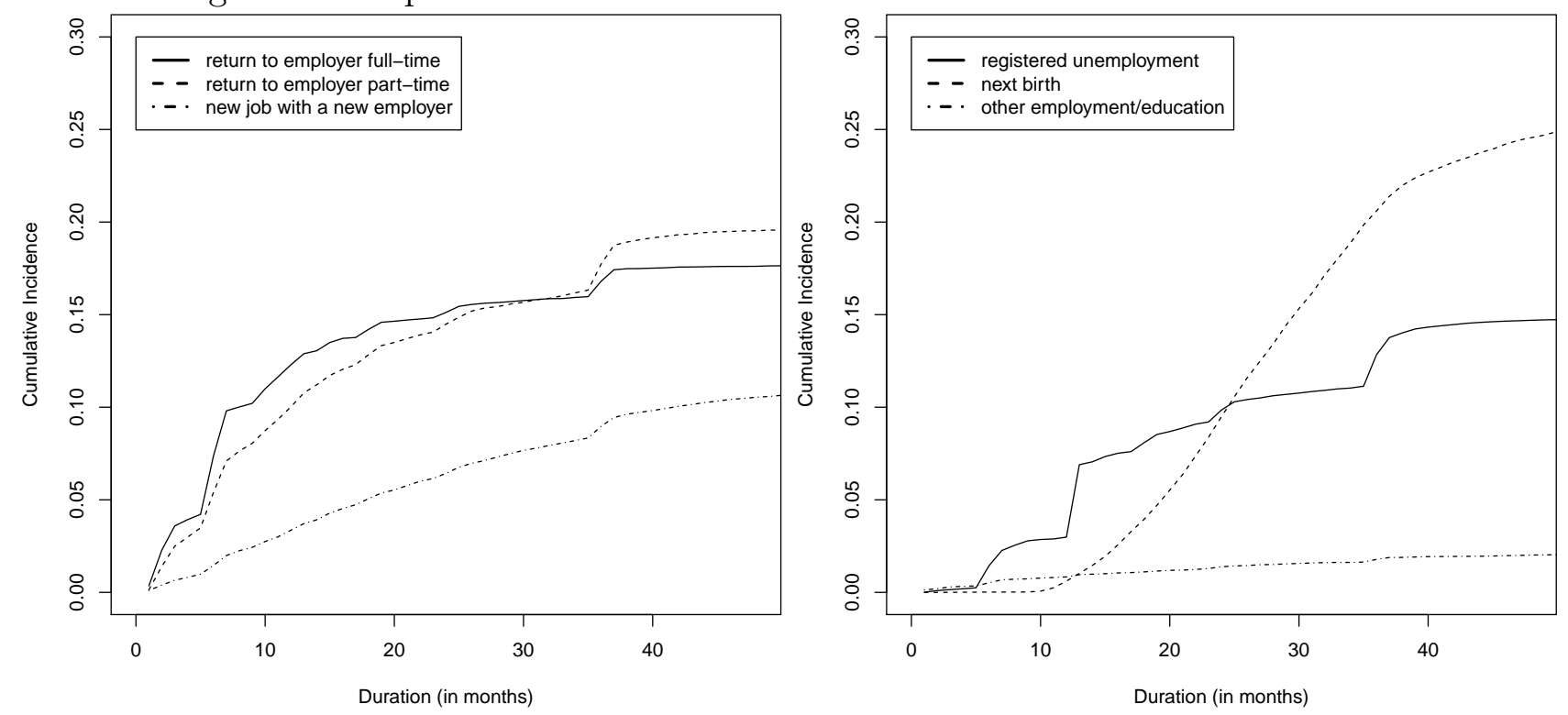

even more so after job protection has been fully exhausted after 36 months. Also, transitions to unemployment seem to be strongly driven by the institutional regulations as has been discussed in the previous section. In fact, transitions to unemployment jump strongly after around 6 , 12 and 36 months which correspond to maximum entitlement periods to job protection and maternity benefits. Transitions to having the next child, on the other hand, increase smoothly after the biological minimum of 10-12 months. Finally, transitions to other exit states such as minor employment or education are only of minor relevance and will thus not be in the focus of the subsequent empirical analysis.

In order to get a more detailed picture whether observed transitions respond to the drop in the utility of staying home as induced by the institutional setting, Figure 3 presents the month on month increase in cumulative incidences for four different periods that reflect the increasing generosity of the leave and maternity benefit regulations. See Figures 4 and 5 (Appendix) for the definition of these periods. The plots clearly suggest that the timing of transitions respond to the institutional design. In particular, mass transitions to the previous employer tend to 
occur when the job protection period (JPP) ends and/or maximum entitlements to maternity benefits (MB) expire. Moreover, the peaks in the return to the former employer occur later as regulations become more generous. This is in line with the literature on the impact of leave policies on the return to work decision of women (compare e.g. Ondrich et el., 2003 and Schönberg and Ludsteck, 2014). Transitions to a new employer also seem to be affected by the institutional setting, but transitions are much less concentrated at few mass points.

Transitions to registered unemployment seem to peak when entitlements to unemployment benefits (UB) are due to expire. This suggests that registering unemployed is part of a woman's choice set rather than being the outcome of an unsuccessful job search. Also, note that women are much more likely to opt for registering unemployed rather than returning to employment if the leave regulations are less generous, see also Figure 1. This indicates that in case of very short job protection periods women are not willing to return to work and register unemployed in order to receive unemployment benefits rather than returning to the previous employer even if that means loosing the legal right of returning to the pre-birth job.

Finally, as one of the most striking findings, the share of females in maternity leave who directly deliver their second child strongly increases with the generosity of leave legislation as can also be seen from Figure 1. Hence, the institutional setting appears to have a strong impact on the timing of birth. While these figures provide some evidence that institutional regulations affect the incidence and timing of transitions to certain states differently, they do not allow for deeper insights into the conditional distributions of transition times. In order to obtain a more detailed picture, we subsequently estimate a multivariate competing risk duration model that relates transitions times to different institutional factors and other characteristics (such as individual-, job- and firm-related factors). 
Figure 3: Month on month increase in unconditional cumulative incidences for 4 periods (as defined in Figures 4 and 5 )

Return to the same employer full-time
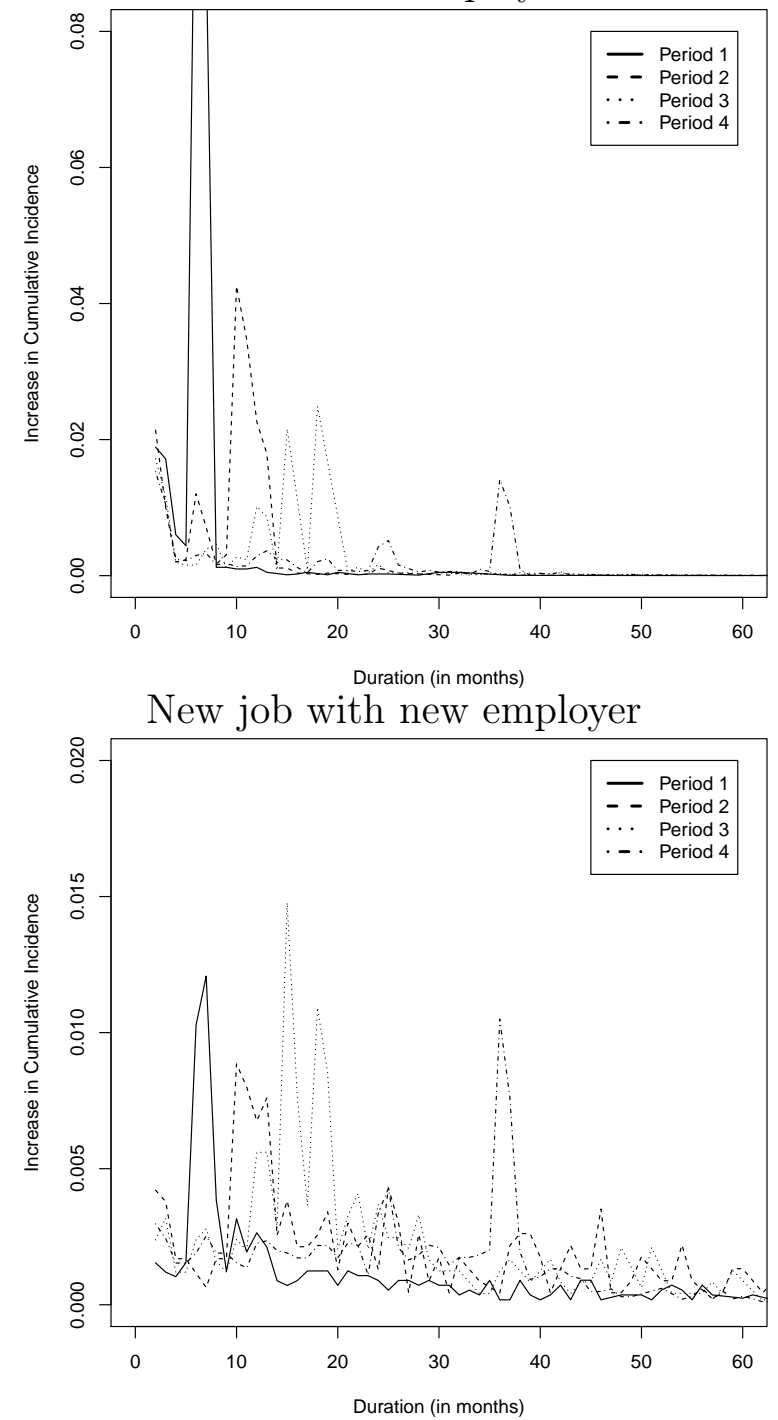

Return to the same employer part-time
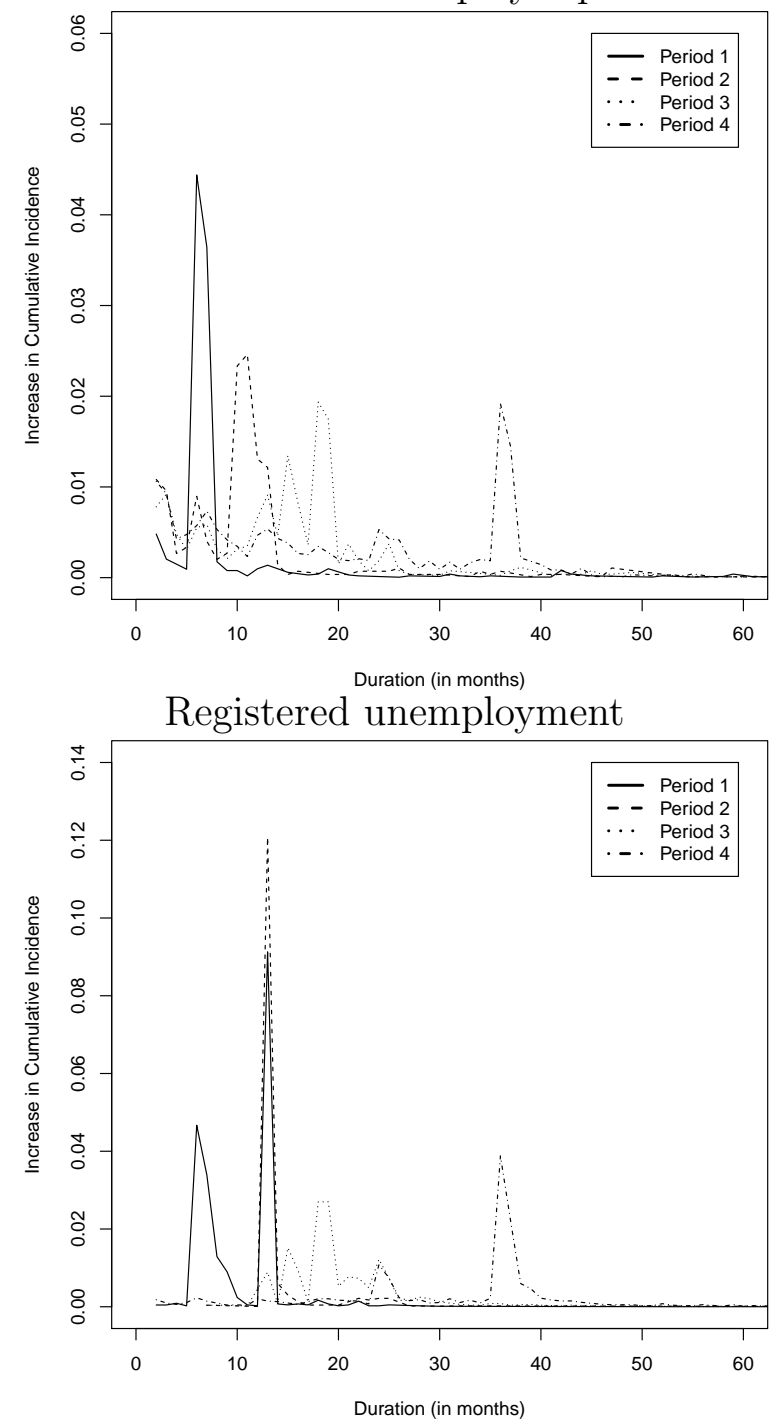

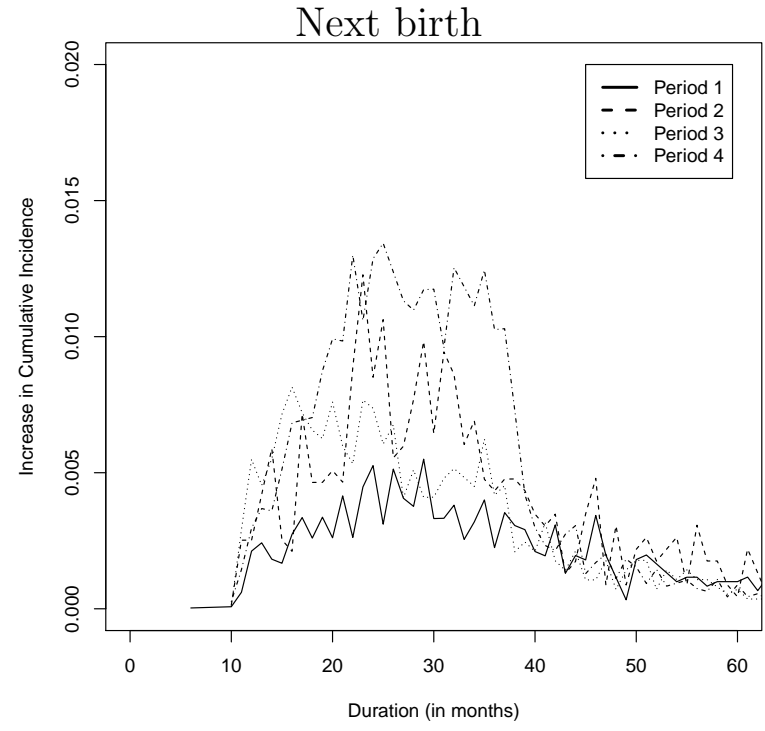




\section{Econometric approach}

As already mentioned in the previous sections, we apply a competing risks duration model with six exit states to relate maternity leave duration to a number of variables. We therefore consider a model with $j=1, \ldots, 6$ competing random variables $T_{j} . \mathbf{X}$ is a $K \times 1$ vector of observable regressors. Due to the competing risks structure it is only possible to observe $(U, \epsilon, \mathbf{X})$ with $\epsilon=\operatorname{argmin}_{j}\left\{T_{j}\right\}$ and $U=\min _{j}\left\{T_{j}\right\}$. Our model also allows for independent censoring with censoring point $C$. Thus, observable duration is $T=\min \{U, C\}$ and let $\Delta=\mathbb{I}(U \leq C) \epsilon$ with indicator function $\mathbb{I}$. Let $\left(t_{j i}, c_{i}, \delta_{i}, \mathbf{x}_{i}\right)$ be $i=1, \ldots, N$ realisations of $\left(T_{j}, C, \Delta, \mathbf{X}\right)$ and $F_{j}(t ; \mathbf{x})=\operatorname{Pr}\left(T_{j} \leq t, \Delta=j ; \mathbf{x}\right)$ be the cumulative incidence curve for risk $j$. The cumulative incidence corresponds to the probability that a transition to state $j$ has occurred by time $t .^{8}$ We consider cumulative incidences in our analysis because they are a convenient tool to describe observable sorting of women into different exit states after birth. In empirical economics, the more frequently used approach to duration analysis is to estimate the marginal distributions for each risk $\operatorname{Pr}\left(T_{j} \leq t ; \mathbf{x}\right)$. Although, this is substantially different to what we consider in this paper, the two approaches are expected to produce very similar conclusions. Another increasingly popular approach in empirical economics is estimating a dynamic discrete choice model (Aguirregabiria and Mira, 2010). In contrast to these models, the model in our analysis neither imposes identifying restrictions on the dependence structure between risks nor does it require a specific covariate structure or explicit parametric assumptions on the distribution of failure times (Assumptions CI-Y, DIS and CLOGIT in Aguirregabiria and Mira, 2010).

In order to estimate the risk-specific cumulative incidence, we apply the model by Fine and

\footnotetext{
${ }^{8}$ For more details about cumulative incidences see Kalbfleisch and Prentice (1980).
} 
Gray (1999) who consider the cause-specific subdistribution hazard function

$$
\begin{aligned}
\lambda_{j}^{s}(t ; \mathbf{x}) & =\lim _{\Delta t \rightarrow 0} \frac{1}{\Delta t} P(t \leq T \leq t+\Delta t, \delta=j ; T \geq t \cup(T \leq t \cap \delta \neq j), \mathbf{x}) \\
& =-\frac{\partial \ln \left[1-F_{j}(t ; \mathbf{x})\right]}{\partial t} .
\end{aligned}
$$

This hazard is difficult to interpret but it is convenient to determine $F_{j}$ from it (see below). Fine and Gray suggest a proportional hazard model of the form

$$
\lambda_{j}^{s}(t ; \mathbf{x})=\lambda_{j 0}^{s}(t) \exp \left(\mathbf{x}^{\prime} \boldsymbol{\beta}_{j}\right)
$$

where $\lambda_{j 0}^{s}(t)$ is the nonparametric baseline subdistribution hazard. In this model the cumulative incidence is

$$
F_{j}(t ; \mathbf{x})=1-\exp \left[-\Lambda_{j 0}^{s}(t) \exp \left(\mathbf{x}^{\prime} \boldsymbol{\beta}_{j}\right)\right]
$$

where $\Lambda_{j 0}^{s}(t ; \mathbf{x})=\int_{0}^{t} \lambda_{j 0}^{s}(u) d u$ is the cumulative baseline subdistribution hazard. The marginal effect of a continuous $x_{k}$ on $F_{j}(t ; \mathbf{x})$ is not simply $\beta_{j k}$ but

$$
\frac{\partial F_{j}(t ; \mathbf{x})}{\partial x_{k}}=\left(F_{j}(t ; \mathbf{x})-1\right) \ln \left(1-F_{j}(t ; \mathbf{x})\right) \beta_{j k}
$$

$\beta_{j k}$ therefore do not have a direct quantitative interpretation but they directly reveal the direction of the marginal effect on the cumulative incidence and the order of marginal effects across regressors as $\left|\frac{\partial F_{j}(t ; \mathbf{x})}{\partial x_{k}}\right|>\left|\frac{\partial F_{j}(t ; \mathbf{x})}{\partial x_{l}}\right|$ iff $\left|\beta_{j k}\right|>\left|\beta_{j l}\right|$. The magnitude of the marginal effect varies with $t$ but its sign does not change in $t$. This restriction on the direction of the marginal effect also exists for the Cox proportional hazard model, where the sign of the marginal effect on the conditional quantile function does not change across quantiles (Koenker and Geling, 2001). In our application we determine marginal effects of continuous covariates as given above. For binary covariates we evaluate $F_{j}$ for both values of the covariate and take the difference in the $F_{j} \mathrm{~s}$. 
For completeness we sketch the likelihood function of the Fine and Gray (1999) model. In absence of censoring they suggest a convenient partial likelihood:

$$
L\left(\boldsymbol{\beta}_{j}\right)=\prod_{i=1}^{N}\left[\frac{\exp \left(\mathbf{x}_{i} \boldsymbol{\beta}_{j}\right)}{\sum_{k \in R_{i}} \exp \left(\mathbf{x}_{i} \boldsymbol{\beta}_{j}\right)}\right]^{\mathbf{I}\left\{\delta_{i}=j\right\}}
$$

with $R_{i}$ defined as $\left\{k:\left(T_{k} \geq T_{i}\right) \cup\left(T_{k} \leq T_{i} \cap \delta_{k} \neq j\right)\right\}$. $R_{i}$ is the risk set at the time of exiting maternity leave for the $i$ 'th female. In this model, parameters are estimated separately for each risk. Fine and Gray also cover estimation in presence of censoring but the likelihood is much more complex and therefore not presented here. $\lambda_{0 j}(t)$ is obtained by a Breslow-type estimator (Breslow, 1974) after $\boldsymbol{\beta}_{j}$ has been estimated. We use the R package cmprsk by Bob Gray for estimation. We use a standard bootstrap procedure for inference. We generate 1,000 samples of size $N$ by drawing with replacement from the estimation sample. The bootstrap variance of the estimator is obtained from the variance of the distribution of estimates obtained with the bootstrap samples.

When we discuss estimation results we focus on the estimated $F_{j}$ as they have a direct interpretation. Therefore, we also consider changes in $F_{j}$ in response to changes in regressors (partial effects). But notice, that each $F_{j}$ is jointly determined by $\operatorname{Pr}\left(T_{j} \leq t ; \mathbf{x}\right)$ for all $j$ and the dependence structure between risks (which is unknown). It is therefore difficult to draw conclusions for changes in $\operatorname{Pr}\left(T_{j} \leq t ; \mathbf{x}\right)$ when $F_{j}$ changes.

Choice of Covariates. We have a comprehensive set of covariates, comprising individual and firm level information in administrative registers, variables computed from the employment trajectories of individuals and linked regional and national aggregated data. We made efforts to collect as many covariates as possible to be able to test the hypotheses of Section 2. In particular, we require observable characteristics for a woman's productivity, pre-birth job match 
quality and the compatibility of her previous job with childcare responsibilities. Table 2 contains the list of covariates and the data sources that will be used to capture these characteristics together with institutional regulations, childcare availability and aggregate economic conditions.

For the individual productivity, we are able to exploit a woman's entire pre-birth employment and earnings history in order to generate useful proxies. Note, however, that the data is highly reliable for information that is mandatory for the social security record such as salaries or occupations, while information that firms transfer on a voluntary basis such as education tends to be much less reliable with a high degree of misclassification and many missing values (compare Fitzenberger et al. 2006). For this reason, we use a woman's pre-birth wage quintile rather than educational attainment as a proxy for a woman's human capital and productivity. In addition, we use information on her pre-birth occupation to define three occupational levels that reflect formal educational requirements and, hence, should also provide a good proxy for educational attainment. In particular, we follow the classification that was developed by Paulus and Matthes (2013) and distinguish between occupations that typically require no vocational training, those that require at least a two-year vocational training and those that necessitate at least a tertiary education or a degree from e.g. advanced technical colleges. While this should already provide a good proxy of someone's human capital, we furthermore add information on total work experience and past unemployment experience to also capture additional differences in individual productivity.

The quality of a woman's job match prior to birth, on the other hand, is captured mainly by tenure as there is ample evidence in the literature that good job matches tend to persist longer. In addition, we use information on a woman's career development prior to birth by creating 
Table 2: Variables for the multivariate model

\begin{tabular}{|c|c|}
\hline Variables & Source \\
\hline \multicolumn{2}{|l|}{ Individual productivity } \\
\hline wage (by quintile within year) & $\mathrm{A}$ \\
\hline total labour market experience (in months) & A \\
\hline past unemployment experiences (yes/no) & $\mathrm{A}$ \\
\hline \multicolumn{2}{|l|}{ Pre-birth job characteristics and match quality } \\
\hline tenure (in months) & $\mathrm{A}$ \\
\hline increase/decrease in pre-birth wage quintile & $\mathrm{A}$ \\
\hline formal education required for occupation (3 categories) & $\mathrm{A}$ \\
\hline occupational risk of shift work/overtime & $\mathrm{A}, \mathrm{F}$ \\
\hline \multicolumn{2}{|l|}{ Pre-birth firm characteristics } \\
\hline firm size (3 dummies) & $\mathrm{A}$ \\
\hline share of female pre-employer staff & $\mathrm{A}$ \\
\hline share of pre-employer staff aged $<30$ & A \\
\hline \multicolumn{2}{|l|}{ Availability of child-care } \\
\hline child-care places per child aged $<3$ & $\mathrm{~B}$ \\
\hline (annual state level data) & \\
\hline \multicolumn{2}{|l|}{ Leave legislation } \\
\hline job protection period & $\mathrm{C}$ \\
\hline ( 4 dummies with $<10,10-12,15-18,36$ months) & \\
\hline maximum maternity benefit entitlements & $\mathrm{C}$ \\
\hline (in Euro, deflated in 1995 prices) & \\
\hline \multicolumn{2}{|l|}{ Labour market conditions } \\
\hline GDP growth rate (national) & $\mathrm{D}$ \\
\hline unemployment rate (by education/year/state) & $\mathrm{E}$ \\
\hline \multicolumn{2}{|l|}{ Further control variables } \\
\hline age & $\mathrm{A}$ \\
\hline inactivity/illness during pregnancy & $\mathrm{A}$ \\
\hline federal state of residence (dummies) & $\mathrm{A}$ \\
\hline decade dummies (1980s, 1990s) & $\mathrm{A}$ \\
\hline
\end{tabular}

A - BASiD, individual level data; B - Federal Statistical Office, annual state-level data;

$\mathrm{C}$ - coded according to regulations as shown in Figures 4 and 5

D - Economic Research Service, United States Department of Agriculture, annual data

E - IABS-04, annual state-level data by three educational levels

F - Mikrozensus (Census) - Federal Statisti22l Office, survey data 
dummy variables for whether a woman climbed up or down the ladder in terms of earnings while working for her pre-birth employer. We consider an upward move prior to conception to be a proxy for a good job match. Finally, we include information about the probability of shift work or overtime by occupational groups since these job characteristics may affect the compatibility of the pre-birth job with new family responsibilities.

In order to proxy for the compatibility of a firm with family responsibilities, we include firm size of the pre-birth employer since the possibility to offer part-time jobs and other family-friendly human resource practices are likely to be more common in larger firms. In addition, firms with a higher share of women among its workforce may be more compatible with childcare responsibilities. In contrast, employers whose staff is pre-dominantly young and thus often childless, likely puts less effort in offering family-friendly conditions.

We include a variable for the availability of public childcare places for children aged below three to capture the institutional setting of a woman's return decision. This information is linked to our individual data based on workplace location and calender time. For the same reason we include dummy variables for the leave legislation that applied at the time when a woman gave birth and also include a measure for the deflated maximum amount of maternity benefits a woman might be entitled to given the birth date of her child. Unfortunately, we do not have individual level data on the actual entitlements to maternity benefits because actual entitlements depend on household income, an information that is not available in our individual data. The actual receipt of benefits does, however, vary less across individuals than the maximum entitlement and therefore we expect that we underestimate the magnitude of the relationship between benefits and maternity duration. 
In addition, we include the national GDP growth rate and the unemployment rate that is observed for a woman's educational level in her state of residence in order to control for the labour market conditions at the time of birth. Further controls that are not directly linked to our hypotheses, but should be included in order to absorb unobserved individual heterogeneity, are the age of the woman when giving birth, an indicator for her health status prior to birth, and her occupation as well as time dummies for the 1980s and 1990s. These time dummies together with the labour market conditions may help to disentangle the effect of institutional changes across time from other influences that may also have changed across time. Finally, we control for the state of residence in order to capture unobserved regional heterogeneity which may stem from economic as well as mentality differences across Germany.

Finally, note that our administrative data do not include household level information that may be relevant for the return decision due to, for example, income effects or the potential availability of childcare by relatives. Given assortative matching, a woman's productivity, for example, is likely to be positively related to the income of her spouse. Hence, given these omitted variables, our analysis can only recover the partial relationship of each of the included variables with the probability of observing a transition, holding all other variables in the model constant. Hence, given the number of covariates included, our estimated marginal effects show interesting partial statistical relationships. The full variable list and descriptive statistics of our sample are given in Table 5 (Appendix). For initial estimation we have included additional variables on individual and regional level but these were dropped as they did only contribute little to the model. This is of course no guarantee that our results are not affected by the omission of any variable. But we expect the results for the main policy related variables to be robust because they are exogenously set by policy makers. 


\section{$5 \quad$ Empirical Results}

We have already discussed unconditional cumulative incidences and how they vary with policy regimes in Section 3. As conditional cumulative incidences on the grounds of the multivariate model confirm these observations we mainly focus on marginal effects in this section. For completeness, we present estimated conditional cumulative incidences for a reference mother in Figure 6 in the Appendix. Although the level of the estimates is partly slightly different, their general shape and the occurrence of mass points is rather similar to their nonparametric unconditional counterparts in Figure 2.

In what follows we focus on presenting and discussing marginal effects on the risk-specific cumulative incidences, i.e. the percentage changes in the probability that a transition to a particular exit state takes place at some point when the covariate changes holding all other variables fixed at the values for the reference mother (compare Table 6). We report these marginal effects after one year and after three years of maternity duration in order to examine potential changes across duration. In contrast to Schönberg and Ludsteck (2014) who consider the event that the mother is employed after up to 5 years after giving birth, we consider only up to three years. We do not consider a longer period because there are only few transitions out of maternity leave after more than three years (compare Figure 3) and cumulative incidences are broadly flat (compare Figure 2). Table 3 presents the corresponding marginal effects for five of the six risks only as the residual category would be difficult to interpret. The full set of estimated model coefficients of the competing risks model is presented in Table 7 in the Appendix for completeness.

With regard to individual characteristics we find that some of them are related to sizable 


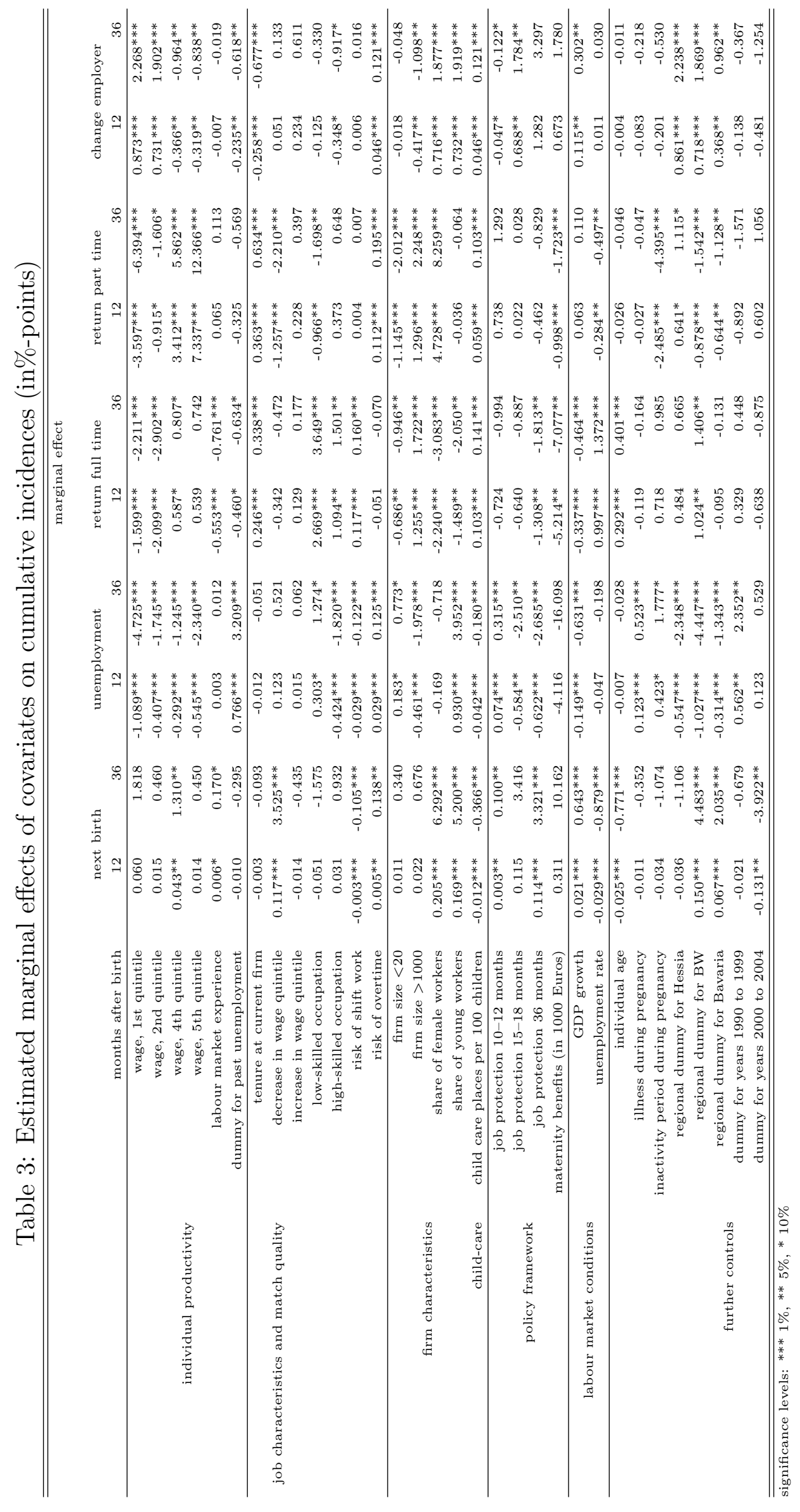


differentiations of transition paths after first birth. In particular, the higher a woman's prebirth wage, the more likely she returns to employment. However, this effect is driven by a differential rate of return to the previous employer. Women earning a pre-birth wage in the highest wage quintile are around 18 percentage points (3 percentage points) more likely to be back in part-time (full-time) with their previous employer three years after birth than women with the lowest wage level, while low-productivity women are 2.5 percentage points more likely to start working for a new employer. This contradicts the evidence in Ejrnæs and Kunze (2013) that women returning to employment are negatively selected, thereby upward biasing the post-birth wage penalty. Our findings rather suggest that women with higher pre-birth wages have both a higher labour market attachment as well as a higher attachment to their previous employer. This attachment appears to be even stronger among women whose pre-birth occupation requires a high level of formal education. They are less likely to change the employer or register unemployed, but more likely to return to the previous job full-time. Hence, even after conditioning on pre-birth wages, labour market attachment seems to be further strengthened among women in high-skilled occupations. This might reflect both women's preferences as well as the need to keep up with demanding and changing tasks requirements in these types of occupations. Interestingly though, women in low-skilled occupations are also more likely to return to the previous job full-time compared to women in medium-skilled occupations. On the other hand, these women are also characterised by a slightly higher probability of unemployment. Hence, these results might reflect that these women face a more difficult job environment that offers less part-time schemes, hence driving women either into returning fulltime or quitting.

With regard to job characteristics, the probability of overtime hours seems to reduce the com- 
patibility of the previous job with family life as these women experience more exits to all states except for the return to the previous employer in full-time. In contrast, there is no similar evidence for shift work. The more likely a job is affected by a shift work pattern, the more likely the mother returns full-time to her previous job and the less likely she terminates the leave period by getting her second child or by becoming unemployed. As expected in section 2 and previously found by Fitzenberger et al. (2016), tenure as an indicator of a good pre-birth job match on the other hand increases the probability of returning to the previous employer and decreases the probability of an employer change. An additional month worked for the pre-birth employer is found to increase the probability of having returned to the employer three years after birth by around half a percentage point for return to full-time or part-time. Mothers who have been recently demoted in the salary distribution are more likely to deliver their second child out of inactivity and are less likely to immediately return the previous employer, thus resulting in prolonged out of work durations. Women who have been promoted recently, on the other hand, seem to have particularly good outside options and are more likely to change the employer. These findings are in line with Winder (2008) who finds evidence that the timing of fertility is negatively related to pre-birth wage growth. Note that if since such an endogeneity of the timing of birth also exists for the first birth, our estimates only reflect a selective group of mothers and cannot be transferred easily to an average women.

Firm characteristics also play an important role. Mothers previously working with small firms are less likely to return and more likely to end up in registered unemployment, while mothers in large firms are more likely to return to the previous employer, albeit more so in part-time. If we assume that large firms are able to offer a human resource management that facilitates the compatibility of work and family responsibilities by offering, among others, more part-time 
schemes, this is in line with our expectation from section 2. Mothers working in firms with a larger share of females are more likely to deliver their second child and change employer but less likely to return full-time. Given that we control for a woman's occupation, this may indicate that firms with a high share of females reflect a work environment that puts less penalty on working part-time or not returning for a prolonged period. In contrast, a pre-birth employer with a very young workforce appears to push mothers to seek alternatives as they are more likely to deliver their second child, end up in unemployment or start working for a new employer, while returning to the pre-birth employer in full-time decreases. As discussed in section 4, this might reflect that firms with very young and often still childless workforces put less effort in being compatible with family responsibilities.

As expected, a better availability of childcare, and hence lower childcare costs, is associated with higher employment rates of mothers and reduces the share of women who register unemployed or have their second child out of inactivity. This is a desirable result both from a policy as well as individual perspective as childcare seems to preserve women's labour force attachment and, hence, likely also future career prospects. In contrast, an extensive job protection period seems to be no good news from the perspective of the previous employer who wants to preserve firm-specific knowledge. At least in case of extensive job protection of 36 months, the share of women returning to the previous workplace tends to decline while the share entering a new job tends to increase with the length of job protection. ${ }^{9}$ Moreover, these effects appear to be stronger as the maternity leave progresses. ${ }^{10}$

\footnotetext{
${ }^{9}$ Note that, although we control for the decade when the birth took place, policy variables may to some extent also absorb general behaviourial trends in calender time.

${ }^{10}$ In contrast, the results from Schönberg and Ludsteck (2014) suggest that the effect of the job protection period on the probability of being in the workforce declines in time from giving birth. However, they compare three with around five years after giving birth, while we only consider up to three years due to a lack of transitions out of maternity leave after three years (compare Figure 3). In fact, it may be reasonable to assume
} 
From a policy perspective, a highly interesting finding is the strong increase in the share of women who deliver their second child out of inactivity as the job protection period extends to three years. In fact, Figure 1 suggests that having the next child actually became the dominant exit state for mothers in the 1990s and the estimates suggest that the extension of the job protection period was the most important driver behind this development. Note, however, that the results also indicate that women who are more likely to have their second child in response to a prolonged job protection period are mainly the ones with prolonged periods of inactivity or unemployment in case of a less generous job protection.

Consistent with our expectation, we find that unfavourable labour market conditions as reflected in a high unemployment rate make women exercise their right to return to their previous employer rather than quitting the job. Moreover, they tend to return in full-time. This may indicate that women want to signal their attachment to their job in order to reduce the risk of being laid off. Moreover, higher unemployment rates may disrupt the spouse's wage income, hence increasing the necessity to earn a higher income share. In fact, periods of high GDP and hence also wage growth, seem to reduce the necessity to work full-time, hence again pointing to the relevance of an income effect.

In order to gain deeper insights into the leverage that certain actors have on women's career paths after first birth, Table 4 reports estimated group effects, where groups of variables are as defined in Table 2. These group effects reflect the difference between the potential maximum and minimum probability of a transition towards exit $r$ for the factors associated with a parthat after the maximum job protection period of 36 months ended, other factors for the decision process gain in importance again. Moreover, the two sets of results are not directly comparable because Schönberg and Ludsteck do not estimate transition probabilities but the crude probability of being employed. 
Table 4: Estimated marginal effects of covariate groups on cumulative incidences (in \%-points)

12 months after birth

\begin{tabular}{rrrrrr}
\hline \hline & next birth & unemployment & return full-time & return part-time & change employer \\
\hline ind. productivity & $0.114^{* *}$ & $1.836^{* * *}$ & $6.869^{* * *}$ & $9.751^{* * *}$ & $1.504^{* * *}$ \\
job charact. \& match qual. & $0.340^{* * *}$ & $1.700^{* * *}$ & $7.772^{* * *}$ & $5.693^{* * *}$ & $2.790^{* * *}$ \\
firm characteristics & $0.210^{* * *}$ & $0.957^{* * *}$ & $3.969^{* * *}$ & $5.142^{* * *}$ & $1.122^{* * *}$ \\
child-care & $0.117^{* * *}$ & $0.418^{* * *}$ & $1.011^{* * *}$ & $0.580^{* * *}$ & $0.454^{* * *}$ \\
policy framework & $0.299^{* *}$ & $1.634^{* * *}$ & $9.601^{* * *}$ & $5.037^{*}$ & 0.980 \\
labour market & $0.129^{* * *}$ & $0.567^{* * *}$ & $3.309^{* * *}$ & $0.837^{* *}$ & $0.381^{*}$ \\
\hline \hline \multicolumn{7}{c}{36 months after birth } & & \\
\hline \hline job charact. \& match qual. & $10.215^{* * *}$ & $7.180^{* * *}$ & $10.598^{* * *}$ & $9.970^{* * *}$ & $7.276^{* * *}$ \\
firm characteristics & $6.397^{* * *}$ & $4.085^{* * *}$ & $5.450^{* * *}$ & $8.946^{* * *}$ & $2.953^{* * *}$ \\
child-care & $3.605^{* * *}$ & $1.776^{* * *}$ & $1.391^{* * *}$ & $1.013^{* * *}$ & $1.190^{* * *}$ \\
nolicy framework & $9.707^{* *}$ & $6.665^{* * *}$ & $13.002^{* * *}$ & $8.673^{*}$ & 2.589 \\
labour market & $3.971^{* * *}$ & $2.401^{* * *}$ & $4.550^{* * *}$ & $1.463^{* *}$ & $1.000^{*}$ \\
\hline \hline
\end{tabular}

significance levels: $* * * 1 \%, * * 5 \%, * 10 \%$

ticular group. ${ }^{11}$ Hence, these effects reflect the relative leverage of the policy framework, firm conditions or individual factors in affecting the different transition types.

First of all, we find that it is mainly unfavorable job characteristics and an extensive leave legislation that push women into the next birth within her inactivity period, especially after 36 months. Similarly, the probability of registering unemployed after 36 months of inactivity is strongly related to the leave legislation, although factors related to individual productivity, job characteristics and match quality are found to play a similarly important role. Whether a mother returns to her former employer, on the other hand, strongly hinges on a mother's individual productivity-related characteristics. Women with favourable individual characteristics

\footnotetext{
${ }^{11}$ For the calculation of these maximum and minimum probabilities, we fix binary variables to zero or one (depending on the sign of their coefficients) and continuous variables at their sample means minus or plus one standard deviation. We do not choose the continuous variables's observed minimum and maximum because the edges of their support could correspond to an outlying observation. Variables which do not belong to the group of interest are held at the values of the reference mother (Table 6, Appendix).
} 
are 17 (9) percentage points more likely to have returned to the former employer in part-time (full-time) after 36 months. Moreover, our findings suggest that former employers may exert some influence on a mother's probability of returning in part-time, while returning full-time seems to be less in the employer's control. In particular, job and firm characteristics have a similar impact on the probability of returning to the former employer in part-time than a woman's individual productivity (19 percentage points after 36 months). In contrast, the probability of returning to the former employer in full-time is more related to leave legislation, especially after 36 months (13 percentage points), while the leave legislation exerts only a comparably small effect on the decision whether to return part-time. For a transition to a new employer, job characteristics and match quality are estimated to possess the strongest partial relationships.

\section{Summary and recommendations}

This paper contributes to the previous international literature on post-maternity labour market outcomes (Baum, 2003, Hanratty and Trzcinski, 2009, Ondrich et al., 2003, Lalive and Zweimüller, 2009, Fitzenberger et al., 2013, Schönberg and Ludsteck, 2014) by estimating transition probabilities for mothers after first birth to different labour market states over a period of more than two decades. By estimating a competing risks model, our study sheds light on the factors affecting the decision process of young mothers after first birth.

First of all, we find profound shifts over a period of almost three decades. Returning part-time to the former employer and giving birth to the second child out of inactivity have strongly increased over the decades, while returning full-time to the former employer and registering unemployed have decreased strongly. We find marked evidence for mass transitions when legal 
job protection periods end. We therefore confirm previous results for the probability of returning to work (Schönberg and Ludsteck, 2014), but show that these patterns are due to changes in transition probabilities and exist for most destination states in our model. Our results therefore confirm patterns of rational behaviour of young mothers when choosing their options.

Our results also provide evidence that the unemployment insurance is systematically misused. Mass transitions into this state when enitilements to matenity benefits or job protection periods end reveal that claiming unemployment benefits is a choice that seems to yield the highest utility level for them. It is therefore advisable to have some hurdles for mothers to enter unemployment while still in job protection. This might then also contribute to a reduction in the considerably longer length of unemployment among females of child-bearing age (Wichert and Wilke, 2008).

We also find that extensive job protection periods of three years are strongly related with a higher probability of giving birth to the second child without having returned to employment before. Moreover, this seems to go along with reduced rates of return to the former employer after three years, suggesting that the role of leave legislation increases in its importance for the return decision with the length of the leave period. Given the results of previous studies (Baum 2002; Waldfogel 1997; Phipps et al. 2001; Ziefle 2004) extensive job protection periods might therefore induce a long term wage penalty for mothers. Our results therefore provide evidence for longer job protection periods being related with longer economic inactivity periods and therefore with increased costs for firms and the economy as a whole.

We also provide evidence for firm characteristics, individual productivity, job match quality and the supply of public child-care being related with the observed differentiation of female careers after first birth, broadly confirming our economic hypotheses. Our finding that the probability 
of returning to employment is higher for mothers with better individual characteristics contrasts previous evidence for a negative selection (Ejrnæs and Kunze, 2013). While characteristics related to a mother's productivity strongly affect the decision whether to return to the previous employer, the policy framework has a notable impact only on the probability of returning fulltime or having the next child. Also, our results indicate that former employers may exert some influence on a mother's probability of returning in part-time, while returning full-time seems to be less in an employer's control. This is an important finding as it allows firms to potentially avoid some costs related to filling the vacant posts temporarily and to retrain and hire new staff (Alewell and Pull, 2001).

\section{References}

[1] Alewell, D. \& Pull, K. (2001). An International Comparison and Assessment of Maternity Leave Legislation. Comparative Labor Law \& Policy Journal, 22(2/3), 297-611.

[2] Anderson, D. J., Binder, M., \& Krause, K. (2003). The motherhood wage penalty revisited: Experience, heterogeneity, work effort, and work-schedule flexibility. Industrial \& Labor Relations Review, 56(2), 273-294.

[3] Angrist, J. D., \& Evans, W. N. (1998). Children and Their Parents' Labor Supply: Evidence from Exogenous Variation in Family Size. The American Economic Review, 88(3), 450-477.

[4] Aguirregabiria, V. \& Mira, P. (2010). Dynamic discrete choice structural models: A survey, Journal of Econometrics, 156, 38-67.

[5] Baum, C. L. (2002). The Efffect of Work Interruptions on Women's Wages. Labour, 16(1), $1-37$. 
[6] Baum, C. L. (2003). The effect of state maternity leave legislation and the 1993 Family and Medical Leave Act on employment and wages. Labour Economics, 10(5), 573-596.

[7] Baxter, J., Hewitt, B. \& Haynes, M. (2008). Life course transitions and housework: Marriage, parenthood, and time on housework. Journal of Marriage and Family, 70, 259-272.

[8] Beblo, M., Bender, S. \& Wolf, E. (2009). Establishment-level wage effects of entering motherhood. Oxford Economic Papers 61, 11-34.

[9] Budig, M. J., \& England, P. (2001). The wage penalty for motherhood. American Sociological Review, 66, 204-225.

[10] Breslow, N. E. (1974). Covariance Analysis of Censored Survival Data. Biometrics, 30, $89-99$.

[11] Ejrnæs, M., \& Kunze, A. (2013). Work and wage dynamics around childbirth. The Scandinavian Journal of Economics, 115(3), 856-877.

[12] Fine J.P. \& Gray R.J. (1999). A proportional hazards model for the subdistribution of a competing risk, Journal of the American Statistical Association, 94(446), 496-509.

[13] Fitzenberger, B., Osikominu, A. \& Völter, R. (2006). Imputation rules to improve the education variable in the IAB employment subsample. Journal of Applied Social Science Studies (Schmollers Jahrbuch), 126(3), 405-436.

[14] Fitzenberger, B., Steffes, S., \& Strittmatter, A. (2016). Return-to-job during and after maternity leave. The International Journal of Human Resource Management, 7(8), 803-831.

[15] Fitzenberger, B., Sommerfeld, K. \& Steffes, S. (2013). Causal effects on employment after first birth - A dynamic treatment approach. Labour Economics, 25, 49-62. 
[16] Frodermann, C., Müller, D, \& Abraham, M. (2013). Determinanten des Wiedereinstiegs von Müttern in den Arbeitsmarkt in Vollzeit oder Teilzeit. Kölner Zeitschrift fr Soziologie und Sozialpsychologie, 65(4), 645-668.

[17] Gangl, M., \& Ziefle, A. (2009). Motherhood, labor force behavior, and women's careers: An empirical assessment of the wage penalty for motherhood in Britain, Germany, and the United States. Demography, 46(2), 341-369.

[18] Gjerdingen, D. K., \& Center, B. A. (2005). First-time parents' postpartum changes in employment, childcare, and housework responsibilities. Social Science Research, 34(1), 103116.

[19] Gustafsson, S. S., Wetzels, C. M., Vlasblom, J. D., \& Dex, S. (1996). Women's labor force transitions in connection with childbirth: A panel data comparison between Germany, Sweden and Great Britain. Journal of Population Economics, 9(3), 223-246.

[20] Gutierrez-Domenech, M. (2005). Employment after motherhood: a European comparison. Labour Economics, 12(1), 99-123.

[21] Hanratty, M., \& Trzcinski, E. (2009). Who benefits from paid family leave? Impact of expansions in Canadian paid family leave on maternal employment and transfer income. Journal of Population Economics, 22(3), 693-711.

[22] Hausman, J.A., \& Woutersen, T. (2014). Estimating a semi-parametric duration model without specifying heterogeneity. Journal of Econometrics, 178(1), 114-131.

[23] Hochfellner, D., Müller, D., \& Wurdack, A. (2012). Biographical Data of Social Insurance Agencies in Germany. Improving the Content of Administrative Data. Schmollers Jahrbuch, $132(3), 443-451$. 
[24] Kalbfleisch, J.D. \& Prentice, R.L. (1980). The statistical analysis of time failure data. John Wiley \& Sone, Inc., New York.

[25] Klerman, J. A., \& Leibowitz, A. (1994). The work-employment distinction among new mothers. Journal of Human Resources, 277-303.

[26] Koenker, R. \& Geling, O. (2001). Reappraising Medfly Longevity: A Quantile Regression Survival Analysis. Journal of the American Statistical Association, 96(454), 458-468.

[27] Korenman, S., \& Neumark, D.. (1992). Marriage, Motherhood, and Wages. The Journal of Human Resources, 27(2), 233255.

[28] Lalive, R., \& Zweimüller, J. (2009). How does parental leave affect fertility and return to work? evidence from two natural experiments. The Quarterly Journal of Economics, 124(3), $1363-1402$.

[29] Leibowitz, A., Klerman, J. A., \& Waite, L. J. (1992). Employment of new mothers and child care choice: Differences by children's age. Journal of Human Resources, 112-133.

[30] Lundberg, S., \& Rose, E. (2000). Parenthood and the earnings of married men and women. Labour Economics, 7(6), 689-710.

[31] Mincer, J., \& Polachek, S. (1974). Family investments in human capital: Earnings of women. In Marriage, family, human capital, and fertility (76-110). NBER.

[32] Ondrich, J., Spiess, C. K., Yang, Q., \& Wagner, G. G. (2000). Full time or part time? German parental leave policy and the return to work after childbirth in Germany, Vol. 18, 41-74, Emerald Group Publishing Limited. 
[33] Ondrich, J., Spiess, C. K., Yang, Q., \& Wagner, G. G. (2003). The liberalization of maternity leave policy and the return to work after childbirth in Germany. Review of Economics of the Household, 1(1-2), 77-110.

[34] Paulus, W. and B. Matthes (2013). Klassifikation der Berufe. Struktur, Codierung und Umsteigeschlssel. FDZ-Methodenreport (8), Bundesagentur für Arbeit, Nürnberg.

[35] Phipps, S., P. Burton, \& Lethbridge, L. . (2001). In and Out of the Labour Market: LongTerm Income Consequences of Child-Related Interruptions to Women's Paid Work. Canadian Journal of Economics 34(2), 411-29.

[36] Schönberg, U., \& Ludsteck, J. (2007). .Maternity Leave Legislation, Female Labor Supply, and the Family Wage Gap, IZA DP No. 2699.

[37] Schönberg, U., \& Ludsteck, J. (2014). Expansions in maternity leave coverage and mothers' labor market outcomes after childbirth. Journal of Labor Economics, 32(3), 469-505.

[38] Schober, P. (2013). The Parenthood Effect on Gender Inequality: Explaining the Change in Paid and Domestic Work When British Couples Become Parents. European Sociological Review 29(1), 74-85.

[39] Viitanen, T. (2012). The motherhood wage gap in the UK over the life cycle, Review of Economics of the Household, 1-18.

[40] Waldfogel, J. (1997). The effect of children on women's wages. American sociological review, 209-217.

[41] Wichert, L. \& Wilke, R.A. (2008). Simple non-parametric estimators for unemployment duration analysis Journal of the Royal Statistical Society: Series C, 57, 117-126. 
[42] Winder, K. L. (2008). Endogenous Fertility and the Motherhood Wage Penalty. Technical report, University of California, Merced.

[43] Ziefle, A. (2004). Die individuellen Kosten des Erziehungsurlaubs. KZfSS Kölner Zeitschrift für Soziologie und Sozialpsychologie, 56(2), 213-231.

\section{A Appendix}

\section{A.1 Tables}




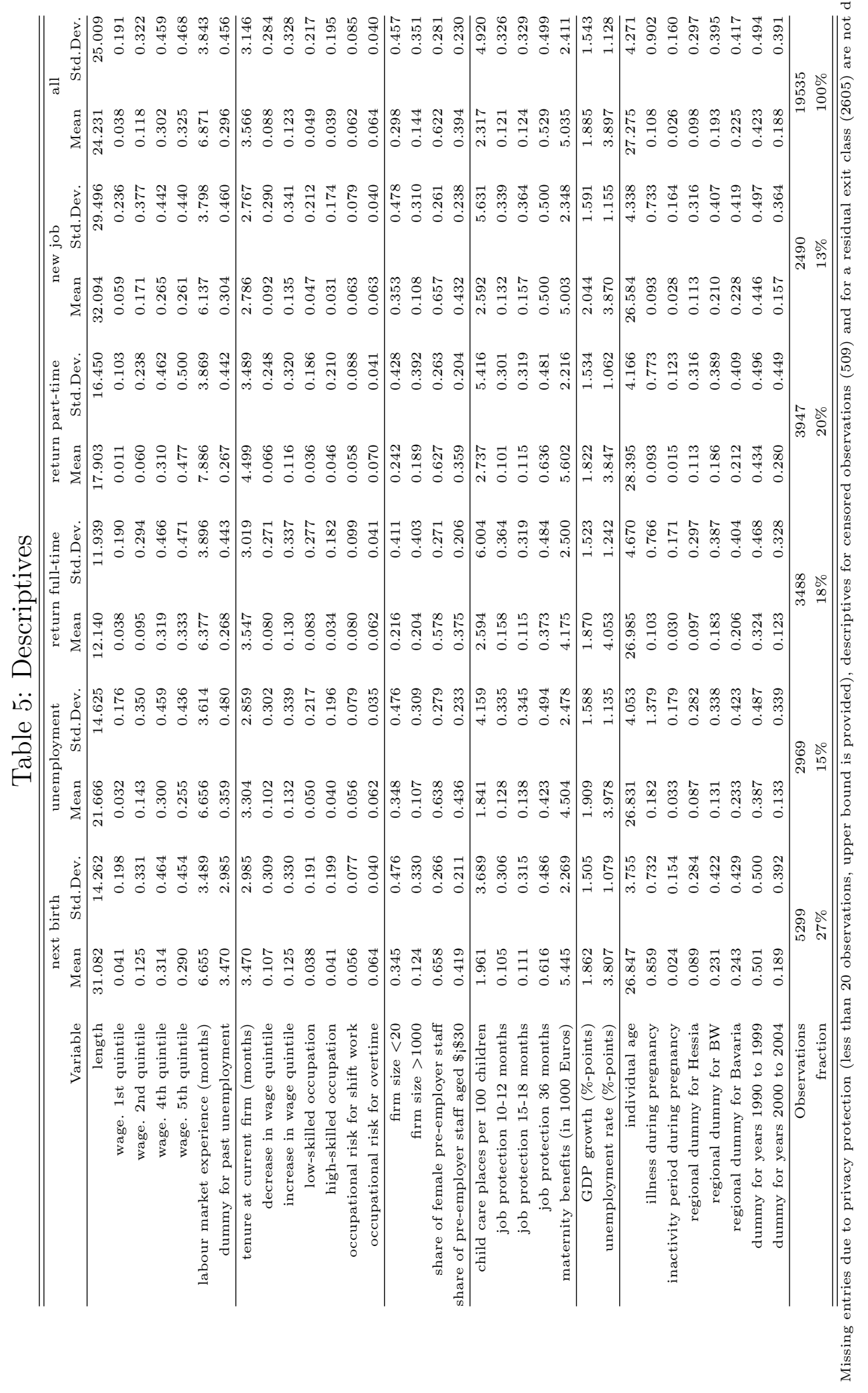


Table 6: Characteristics of the reference person used for the plots in Figures 3 and 6

\begin{tabular}{|c|c|}
\hline Variable & Value \\
\hline wage & 3rd quintile \\
\hline labour market experience (months) & 6.871 \\
\hline dummy for past unemployment & 0 \\
\hline tenure at current firm (months) & 3.566 \\
\hline decrease in wage quintile & 0 \\
\hline increase in wage quintile & 0 \\
\hline firm size & 20 to 1000 \\
\hline share of female workers & 0.622 \\
\hline share of young workers & 0.394 \\
\hline firm information missing & 0 \\
\hline child care places per 100 children & 2.316 \\
\hline job protection & 36 months \\
\hline maternity benefits (in 1000 Euros) & 5.035 \\
\hline GDP growth (\%-points) & 1.885 \\
\hline unemployment rate (\%-points) & 3.897 \\
\hline individual age & 27.276 \\
\hline inactivity period during pregnancy & 0 \\
\hline illness during pregnancy & 0 \\
\hline formal education required for occupation & voc. training \\
\hline risk for shift work (\%-points) & 6.2 \\
\hline risk for overtime (\%points) & 6.4 \\
\hline regional dummy & Northrhine-Westfalia \\
\hline decade & 2000 to 2004 \\
\hline
\end{tabular}




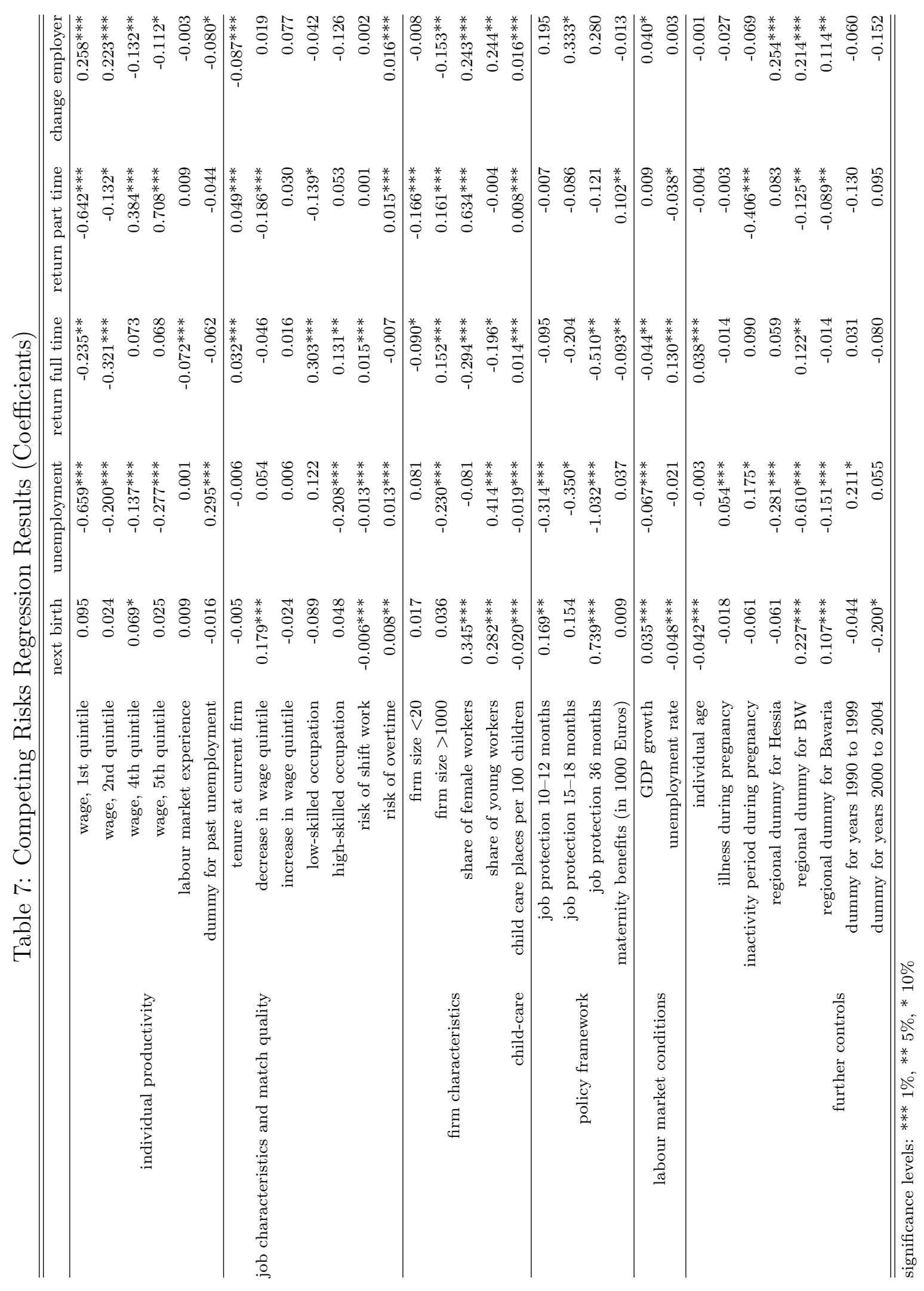




\section{A.2 Figures}

Figure 4: Job protection periods and duration of maternity benefits by regime (with start date)

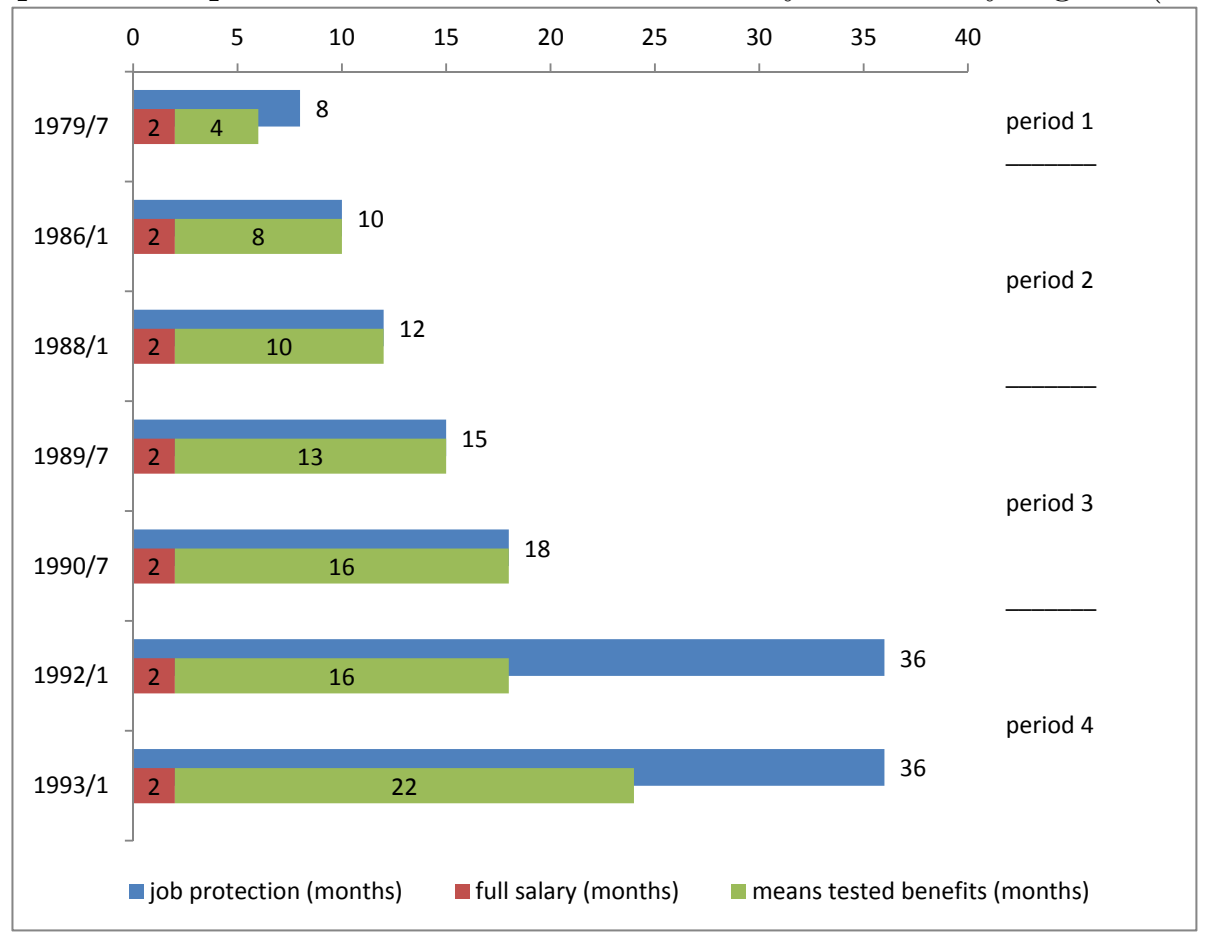

Figure 5: Maximum cumulative amount of means tested maternity benefits by regime (with start date)

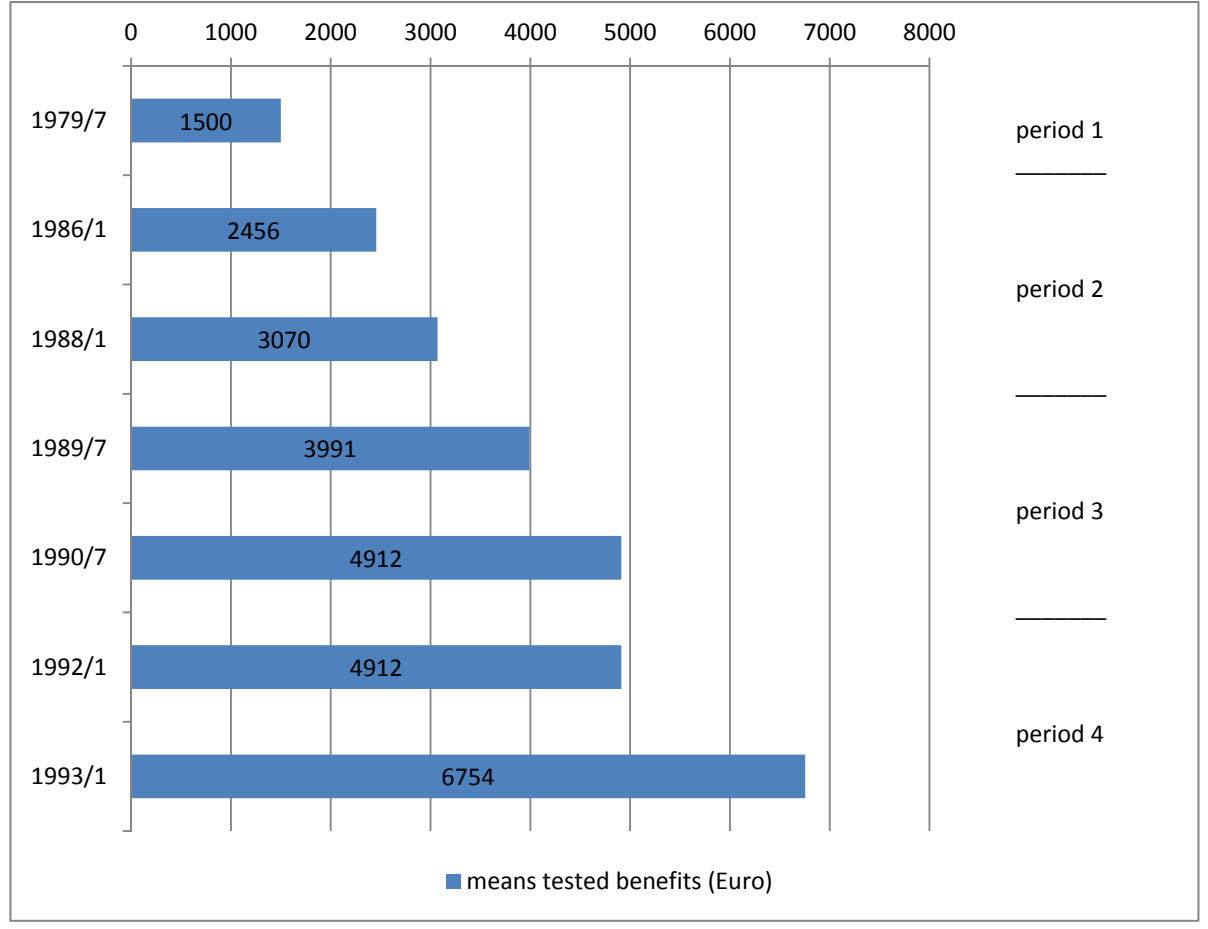


Figure 6: Estimates of cumulative incidences for the reference person (see Table 6).
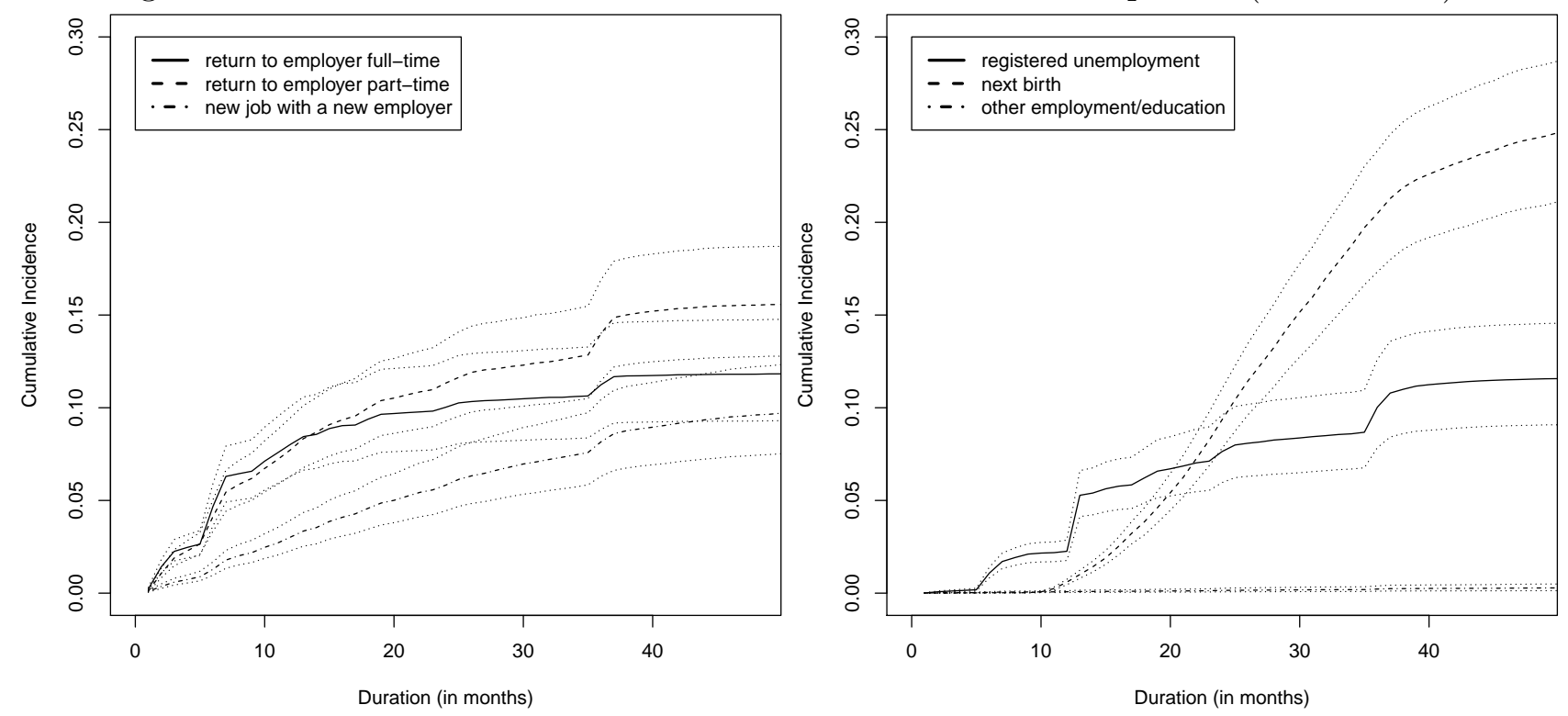